\title{
(6) OPEN ACCESS \\ Nintedanib in patients with idiopathic pulmonary fibrosis and preserved lung volume
}

\author{
Martin Kolb, ${ }^{1}$ Luca Richeldi, ${ }^{2}$ Jürgen Behr, ${ }^{3}$ Toby M Maher, ${ }^{4,5}$ Wenbo Tang, ${ }^{6}$ \\ Susanne Stowasser, ${ }^{7}$ Christoph Hallmann, ${ }^{7}$ Roland M du Bois ${ }^{8}$
}

- Additional material is

published online only. To view please visit the journal online (http://dx.doi.org/10.1136/ thoraxjnl-2016-208710).

\section{'McMaster University,} Hamilton, Ontario, Canada ${ }^{2}$ National Institute for Health Research Southampton Respiratory Biomedical Research Unit and Clinical and Experimental Sciences, University of Southampton, Southampton, UK ${ }^{3}$ Medizinische Klinik und Poliklinik V, University of Munich and Asklepios Klinik München-Gauting, Member of the German Center for Lung Research, Munich, Germany ${ }^{4} \mathrm{NIHR}$ Biomedical Research Unit Royal Brompton Hospital, London, UK

${ }^{5}$ Fibrosis Research Group, National Heart and Lung Institute, Imperial College, London, UK

${ }^{6}$ Boehringer Ingelheim

Pharmaceuticals Inc., Ridgefield, Connecticut, USA

${ }^{7}$ Boehringer Ingelheim Pharma GmbH \& Co. KG, Ingelheim am Rhein, Germany

${ }^{8}$ Imperial College, London, UK

\section{Correspondence to}

Dr Martin Kolb, Department of Medicine and Pathology/

Molecular Medicine, McMaster University, 50 Charlton Ave. E., Hamilton, ON L8N 4A6

Canada; kolbm@mcmaster.ca

Received 30 March 2016 Revised 23 August 2016 Accepted 27 August 2016 Published Online First 26 September 2016

\section{(a) CrossMark}

To cite: Kolb M, Richeldi L, Behr J, et al. Thorax 2017;72:340-346.

\section{ABSTRACT}

Rationale There is no consensus as to when treatment for idiopathic pulmonary fibrosis (IPF) should be initiated. Some physicians prefer not to treat patients with preserved lung volume.

Objective To investigate whether patients with IPF and preserved lung volume receive the same benefit from nintedanib as patients with more impaired lung volume. Methods Post hoc subgroup analyses of pooled data from the two replicate phase III INPULSIS trials by baseline FVC $\%$ predicted $(\leq 90 \%$, $>90 \%)$.

Results At baseline, 274 patients had FVC >90\% predicted and 787 patients had FVC $\leq 90 \%$ predicted. In patients treated with placebo, the adjusted annual rate of decline in FVC was consistent between patients with FVC $>90 \%$ predicted and FVC $\leq 90 \%$ predicted $(-224.6 \mathrm{~mL} / \mathrm{year}$ and $-223.6 \mathrm{~mL} /$ year, respectively). There was no statistically significant difference between these subgroups in the effect of nintedanib on annual rate of decline in FVC, change from baseline in St George's Respiratory Questionnaire total score or time to first acute exacerbation. In patients with baseline FVC $>90 \%$ predicted and $\leq 90 \%$ predicted, respectively, the adjusted annual rate of decline in FVC with nintedanib was $-91.5 \mathrm{~mL} /$ year (difference vs placebo: $133.1 \mathrm{~mL} /$ year (95\% Cl 68.0 to 198.2$)$ ) and $-121.5 \mathrm{~mL} /$ year (difference vs placebo: $102.1 \mathrm{~mL} /$ year $(95 \% \mathrm{Cl} 61.9$ to 142.3)). Adverse events associated with nintedanib were similar in both subgroups.

Conclusions Patients with IPF and preserved lung volume (FVC $>90 \%$ predicted) have the same rate of FVC decline and receive the same benefit from nintedanib as patients with more impaired lung volume. Trial registration number NCT01335464 and NCT01335477.

\section{INTRODUCTION}

Idiopathic pulmonary fibrosis (IPF) is a specific form of interstitial pneumonia associated with chronic dyspnoea and cough, and the progressive loss of lung function. ${ }^{1}$ The clinical course of IPF is variable and difficult to predict, with some patients progressing rapidly, others relatively slowly and some experiencing acute deteriorations in respiratory function that are associated with high morbidity and mortality. ${ }^{2}$ A decline in FVC reflects disease progression in patients with IPF and is predictive of mortality. ${ }^{3-6}$ Data from phase II-III trials in patients with IPF and mild or moderate impairment of lung function suggest that the decline in FVC in patients receiving placebo is $\sim 200 \mathrm{~mL} /$ year. $^{7-12}$

\section{Key messages}

What is the key question?

- Do patients with idiopathic pulmonary fibrosis (IPF) and preserved lung volume receive the same benefit from nintedanib as patients with more impaired lung volume?

\section{What is the bottom line?}

- Patients with IPF and FVC $>90 \%$ predicted at baseline have the same rate of FVC decline and receive the same benefit from nintedanib as patients with more impaired lung volume.

\section{Why read on?}

- These data provide, for the first time, evidence in a significant subgroup of patients with preserved lung volume to support the concept of offering early treatment to patients with IPF.

Nintedanib is an intracellular inhibitor of tyrosine kinases $^{13}$ that has been approved for the treatment of IPF in several countries and regions including the USA, EU, Canada and Japan. Nintedanib received a conditional recommendation for use in the treatment of IPF in the latest international clinical practice guideline. ${ }^{14}$ The efficacy and safety of nintedanib $150 \mathrm{mg}$ twice daily in patients with IPF were assessed in the two replicate, randomised, placebo-controlled, 52-week, phase III INPULSIS trials (NCT01335464 and NCT01335477). ${ }^{12}$ In both INPULSIS trials, nintedanib significantly reduced the annual rate of decline in FVC (primary endpoint). A benefit of nintedanib versus placebo on the key secondary endpoints of time to first investigator-reported acute exacerbation and change from baseline in St George's Respiratory Questionnaire (SGRQ) total score over 52 weeks was observed in INPULSIS-2, but not in INPULSIS-1. The adverse events most frequently associated with nintedanib were gastrointestinal events, particularly diarrhoea. ${ }^{12}$

IPF is commonly described using the terms 'mild', 'moderate' and 'severe', or 'early' and 'advanced'. ${ }^{15}$ However, there is no standard definition for what constitutes 'mild disease' or 'marginally impaired lung function' in patients with IPF and no consensus regarding at which point therapy should be initiated or stopped, particularly as no treatment has been shown to provide significant 
symptomatic benefit. Some national guidelines use thresholds of FVC as a percentage of the predicted value (FVC \% predicted) to determine when pharmacological treatment for IPF should be used $^{16}$ but these are not based on scientific evidence.

The inclusion criteria used in the INPULSIS trials set no upper limit on FVC \% predicted. A recently published prespecified subgroup analysis demonstrated a consistent effect of nintedanib in subgroups of patients with FVC $\leq$ and $>70 \%$ predicted at baseline. ${ }^{17}$ In this analysis, we investigated whether patients with IPF and preserved lung volume (FVC $>90 \%$ predicted) received the same benefit from nintedanib as patients with greater impairment in lung volume. Some of these results have been reported as an abstract. ${ }^{18}$

\section{METHODS}

The design of the INPULSIS trials has been described. ${ }^{12}$ The clinical trial protocol was approved by an Independent Ethics Committee and/or Institutional Review Board at all the participating centres. All patients provided written informed consent prior to study entry. Eligible patients had been diagnosed with IPF within the previous 5 years and had an $\mathrm{FVC} \geq 50 \%$ predicted (no upper threshold), a diffusion capacity of the lung for carbon monoxide $\left(\mathrm{TL}_{\mathrm{CO}}\right) 30 \%$ to $79 \%$ predicted and a $\mathrm{FEV}_{1} /$ FVC ratio $\geq 0.7$. Patients were randomised to receive nintedanib $150 \mathrm{mg}$ twice daily or placebo in a 3:2 ratio.

Post hoc analyses in subgroups of patients with baseline FVC $>90 \%$ versus $\leq 90 \%$ predicted were conducted using pooled data from the two INPULSIS trials. Analyses were conducted in patients who received $\geq 1$ dose of study drug. Analyses were conducted on the primary endpoint (annual rate of decline in FVC) and the key secondary endpoints (time to first investigator-reported acute exacerbation and change from baseline in SGRQ total score) by repeating the primary analysis for each endpoint (described in ref. 12) in each subgroup.
The statistical model used for the primary analysis assumed that missing data were missing at random; missing data were not imputed. For the primary endpoint, the terms subgroup and an interaction term treatment-by-time-by-subgroup were included in the model. For the key secondary endpoints, the terms subgroup and an interaction term treatment-by-subgroup were included in the model.

Time to disease progression over 52 weeks, defined as an absolute decline in FVC $\geq 10 \%$ predicted or death, or an absolute decline in $\mathrm{FVC} \geq 5 \%$ predicted or death, was assessed using a Cox's regression model with the terms subgroup and an interaction term treatment-by-subgroup included. Safety was assessed through clinical and laboratory evaluation and recording adverse events with onset after the first dose and up to 28 days after the last dose of study drug. Adverse events were coded using the Medical Dictionary for Regulatory Activities (MedDRA), V.16.1. Safety analyses were descriptive.

\section{RESULTS}

\section{Patients}

A total of $274(25.8 \%)$ patients had baseline FVC $>90 \%$ predicted (166 treated with nintedanib, 108 treated with placebo) and $787(74.2 \%)$ patients had baseline FVC $\leq 90 \%$ predicted (472 treated with nintedanib, 315 treated with placebo). Baseline characteristics of patients in each subgroup are presented in table 1.

Compared with patients with FVC $\leq 90 \%$ predicted, patients with $\mathrm{FVC}>90 \%$ predicted had a shorter time since diagnosis, higher $\mathrm{TL}_{\mathrm{CO}} \%$ predicted and lower SGRQ total score (indicating better health-related quality of life), and were more likely to have centrilobular emphysema (based on high-resolution CT scan) and to be female. Within each subgroup, baseline characteristics were similar between the nintedanib and placebo groups.

Table 1 Baseline characteristics by subgroup (mean \pm SD or $\mathrm{n}(\%)$ )

\begin{tabular}{|c|c|c|c|c|}
\hline & \multicolumn{2}{|l|}{ FVC $>90 \%$ predicted } & \multicolumn{2}{|l|}{ FVC $\leq 90 \%$ predicted } \\
\hline & Nintedanib $(n=166)$ & Placebo $(n=108)$ & Nintedanib $(n=472)$ & Placebo $(n=315)$ \\
\hline Age, years & $68.2 \pm 8.0$ & $67.5 \pm 7.6$ & $66.1 \pm 8.1$ & $66.8 \pm 8.0$ \\
\hline Male & $121(72.9)$ & $75(69.4)$ & $386(81.8)$ & $259(82.2)$ \\
\hline \multicolumn{5}{|l|}{ Race } \\
\hline White & $87(52.4)$ & $61(56.5)$ & $273(57.8)$ & $187(59.4)$ \\
\hline Asian & $54(32.5)$ & $37(34.3)$ & $140(29.7)$ & $91(28.9)$ \\
\hline Black & $0(0.0)$ & $0(0.0)$ & $2(0.4)$ & $0(0.0)$ \\
\hline Missing* & $25(15.1)$ & $10(9.3)$ & $57(12.1)$ & $37(11.7)$ \\
\hline \multicolumn{5}{|l|}{ Smoking status } \\
\hline Never smoked & $45(27.1)$ & $33(30.6)$ & $129(27.3)$ & $89(28.3)$ \\
\hline Ex-smoker & $110(66.3)$ & $66(61.1)$ & $325(68.9)$ & $217(68.9)$ \\
\hline Current smoker & $11(6.6)$ & $9(8.3)$ & $18(3.8)$ & $9(2.9)$ \\
\hline Time since diagnosis, years & $1.4 \pm 1.2$ & $1.3 \pm 1.3$ & $1.7 \pm 1.4$ & $1.7 \pm 1.3$ \\
\hline Centrilobular emphysema & $77(46.4)$ & $53(49.1)$ & $177(37.5)$ & $113(35.9)$ \\
\hline FVC, mL & $3306 \pm 821$ & $3420 \pm 945$ & $2505 \pm 610$ & $2491 \pm 598$ \\
\hline FVC, \% predicted & $103.1 \pm 11.0$ & $103.9 \pm 12.4$ & $71.5 \pm 10.7$ & $70.8 \pm 10.6$ \\
\hline $\mathrm{FEV}_{1} / \mathrm{FVC}$ ratio, $\%$ & $79.2 \pm 6.0$ & $78.7 \pm 5.6$ & $82.5 \pm 5.5$ & $82.7 \pm 5.8$ \\
\hline Diffusion capacity of the lung for carbon monoxide, \% predicted $t$ & $52.8 \pm 13.3$ & $52.3 \pm 12.6$ & $45.5 \pm 13.1$ & $45.1 \pm 13.2$ \\
\hline St George's Respiratory Questionnaire total scoreł & $32.2 \pm 18.5$ & $31.3 \pm 15.2$ & $42.0 \pm 18.7$ & $42.4 \pm 18.7$ \\
\hline Composite physiologic index§ & $37.3 \pm 9.8$ & $37.2 \pm 9.2$ & $49.0 \pm 9.5$ & $49.5 \pm 9.7$ \\
\hline
\end{tabular}

* In France, regulation did not permit the collection of data on race.

$\mathrm{tn}=314$ for placebo in FVC $\leq 90 \%$ predicted subgroup.

$\neq n=160$ for nintedanib and $n=106$ for placebo in FVC $>90 \%$ predicted subgroup and $n=464$ for nintedanib and $n=313$ for placebo in FVC $\leq 90 \%$ predicted subgroup.

$\S n=314$ for placebo in FVC $\leq 90 \%$ predicted subgroup. 


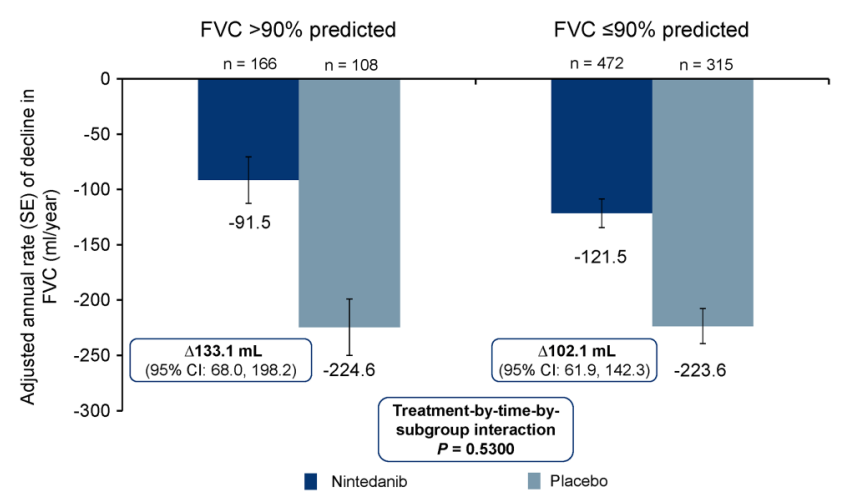

Figure 1 Adjusted annual rate (SE) of decline in FVC (mL/year) by subgroup.

In the subgroup of patients with baseline FVC $>90 \%$ predicted, 43 patients (25.9\%) in the nintedanib group and 11 patients $(10.2 \%)$ in the placebo group prematurely discontinued trial medication. In the subgroup of patients with baseline FVC $\leq 90 \%$ predicted, 113 patients $(23.9 \%)$ in the nintedanib group and 69 patients $(21.9 \%)$ in the placebo group prematurely discontinued trial medication.

In patients with baseline FVC $>90 \%$ predicted, mean (SD) duration of exposure was 10.1 (3.6) months and 11.3 (2.0) months in the nintedanib and placebo groups, respectively. In patients with baseline FVC $\leq 90 \%$ predicted, mean (SD) duration of exposure was 10.4 (3.3) months and 10.7 (3.0) months in the nintedanib and placebo groups, respectively.

\section{Annual rate of decline in FVC}

In patients with baseline FVC $>90 \%$ predicted, the adjusted annual rate of decline in FVC was $-91.5 \mathrm{~mL} /$ year in the nintedanib group and $-224.6 \mathrm{~mL} / \mathrm{year}$ in the placebo group (difference of $133.1 \mathrm{~mL} /$ year (95\% CI 68.0 to 198.2$)$ ) (figure 1$)$. In patients with baseline FVC $\leq 90 \%$ predicted, the adjusted annual rate of decline in FVC was $-121.5 \mathrm{~mL} /$ year in the nintedanib group and $-223.6 \mathrm{~mL} / \mathrm{year}$ in the placebo group (difference of $102.1 \mathrm{~mL} /$ year (95\% CI 61.9 to 142.3 )) (figure 1). The treatment-by-subgroup interaction $\mathrm{p}$ value was not significant $(p=0.530)$, indicating that the treatment effect of nintedanib was not different between the subgroups. The primary endpoint results were supported by the observed changes from baseline in
FVC over time in each subgroup (see online supplementary figure S1).

\section{Disease progression}

In patients with baseline FVC $>90 \%$ predicted, the $\mathrm{HR}$ for time to an absolute decline in FVC $\geq 10 \%$ predicted or death was 0.59 (95\% CI 0.38 to 0.89 ) in favour of nintedanib (table 2; figure 2). In patients with baseline FVC $\leq 90 \%$ predicted, the corresponding HR was 0.61 (95\% CI 0.48 to 0.78 ) in favour of nintedanib (table 2; figure 2). The treatment-by-subgroup interaction $\mathrm{p}$ value was not significant $(p=0.830)$, indicating that the treatment effect of nintedanib was not different between the subgroups by baseline FVC. In both subgroups, most patients who met this endpoint did so based on absolute decline in FVC $\geq 10 \%$ predicted rather than death, but the proportion of patients who died over 52 weeks was higher in patients with FVC $\leq 90 \%$ predicted than $>90 \%$ predicted at baseline (table 2 ).

In patients with baseline FVC $>90 \%$ predicted, the $\mathrm{HR}$ for time to an absolute decline in $\mathrm{FVC} \geq 5 \%$ predicted or death over 52 weeks was 0.67 (95\% CI 0.50 to 0.90 ) in favour of nintedanib; the proportion of patients who met this endpoint was $60.2 \%$ in the nintedanib group and $77.8 \%$ in the placebo group. In patients with baseline FVC $\leq 90 \%$ predicted, the corresponding HR was 0.59 (95\% CI 0.49 to 0.71 ) in favour of nintedanib (figure 3 ); the proportion of patients who met this endpoint was $48.7 \%$ in the nintedanib group and $69.5 \%$ in the placebo group. The treatment-by-subgroup interaction $\mathrm{p}$ value was not significant $(p=0.486)$, indicating that the treatment effect of nintedanib was not different between the subgroups by baseline FVC.

\section{Acute exacerbations}

In patients with baseline $\mathrm{FVC}>90 \%$ predicted, the $\mathrm{HR}$ for time to first acute exacerbation was 0.46 (95\% CI 0.09 to 2.48 ) in favour of nintedanib (figure 4 ); the proportion of patients with $\geq 1$ acute exacerbation was $1.8 \%$ in the nintedanib group and $2.8 \%$ in the placebo group (three patients in each group). In patients with baseline FVC $\leq 90 \%$ predicted, the HR for time to first acute exacerbation was 0.66 (95\% CI 0.39 to 1.11 ) in favour of nintedanib (figure 4); the proportion of patients with $\geq 1$ acute exacerbation was $5.9 \%$ in the nintedanib group and $9.2 \%$ in the placebo group (28 and 29 patients, respectively). The treatment-by-subgroup interaction $p$ value was not

Table 2 Proportions of patients with disease progression over 52 weeks and HR for time to first event by subgroup

\begin{tabular}{|c|c|c|c|c|}
\hline & \multicolumn{2}{|l|}{ FVC $>90 \%$ predicted } & \multicolumn{2}{|l|}{ FVC $\leq 90 \%$ predicted } \\
\hline & Nintedanib $(n=166)$ & Placebo $(n=108)$ & Nintedanib $(n=472)$ & Placebo $(n=315)$ \\
\hline Absolute decline in FVC $\geq 10 \%$ predicted or death, $n(\%)$ & $44(26.5)$ & $44(40.7)$ & $129(27.3)$ & $131(41.6)$ \\
\hline $\mathrm{HR}(95 \% \mathrm{Cl})$ & \multicolumn{2}{|c|}{$0.59(0.38$ to 0.89$)$} & \multicolumn{2}{|c|}{$0.61(0.48$ to 0.78$)$} \\
\hline Treatment-by-subgroup interaction & \multicolumn{4}{|c|}{$p=0.8304$} \\
\hline \multicolumn{5}{|l|}{ Criterion reached first, $\mathrm{n}(\%)$} \\
\hline Absolute decline in $\mathrm{FVC} \geq 10 \%$ predicted & $42(25.3)$ & $43(39.8)$ & $106(22.5)$ & $110(34.9)$ \\
\hline Death & $2(1.2)$ & $1(0.9)$ & $23(4.9)$ & $21(6.7)$ \\
\hline Absolute decline in FVC $\geq 5 \%$ predicted or death, $\mathrm{n}(\%)$ & $100(60.2)$ & $84(77.8)$ & $230(48.7)$ & $219(69.5)$ \\
\hline $\mathrm{HR}(95 \% \mathrm{Cl})$ & \multicolumn{2}{|c|}{$0.67(0.50$ to 0.90$)$} & \multicolumn{2}{|c|}{0.59 (0.49 to 0.71$)$} \\
\hline Treatment-by-subgroup interaction & \multicolumn{4}{|c|}{$p=0.4862$} \\
\hline \multicolumn{5}{|l|}{ Criterion reached first, $\mathrm{n}(\%)$} \\
\hline Absolute decline in FVC $\geq 5 \%$ predicted & 99 (59.6) & $83(76.9)$ & $218(46.2)$ & $209(66.3)$ \\
\hline Death & $1(0.6)$ & $1(0.9)$ & $12(2.5)$ & $10(3.2)$ \\
\hline
\end{tabular}




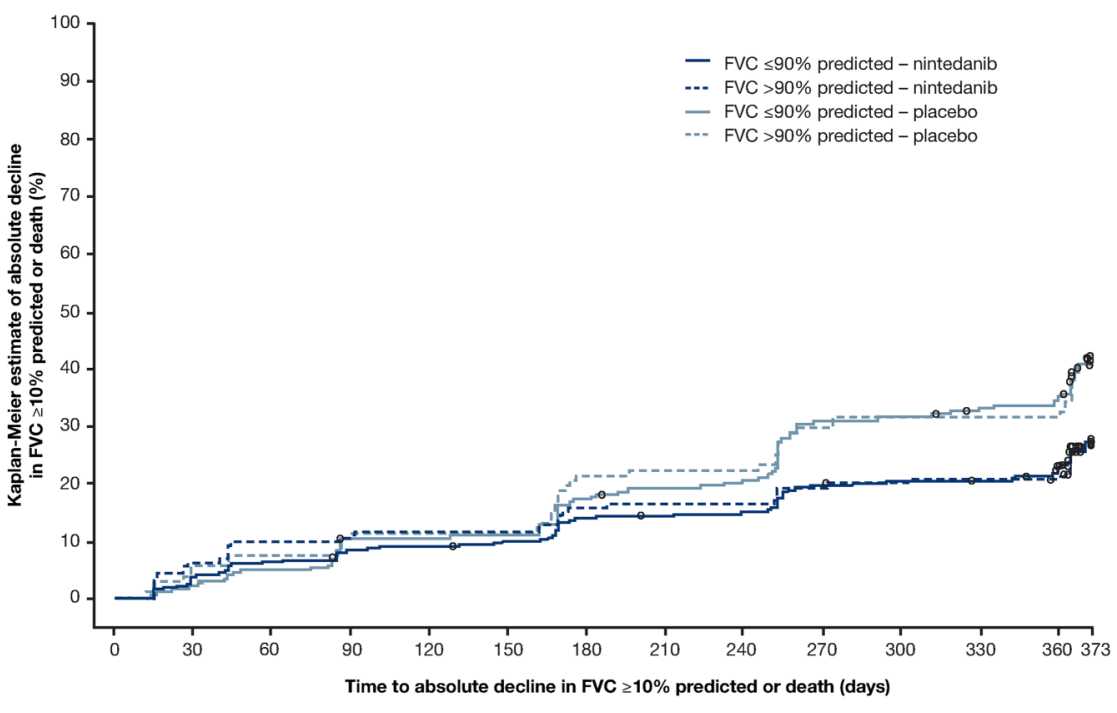

\begin{tabular}{|c|c|c|c|c|c|c|c|c|c|c|c|c|c|}
\hline Number at risk & & & & & & & & & & & & & \\
\hline FVC $\leq 90 \%$ predicted - nintedanib & 472 & 455 & 443 & 432 & 429 & 424 & 404 & 402 & 399 & 377 & 374 & 373 & 363 \\
\hline FVC $>90 \%$ predicted - nintedanib & 166 & 156 & 150 & 149 & 147 & 147 & 139 & 138 & 138 & 133 & 131 & 130 & 129 \\
\hline FVC s $90 \%$ predicted - placebo & 315 & 309 & 300 & 281 & 281 & 279 & 260 & 253 & 249 & 217 & 214 & 209 & 203 \\
\hline $\mathrm{V} \mathrm{VC}>90 \%$ predicted - placebo & 108 & 102 & 100 & 96 & 96 & 96 & 85 & 84 & 84 & 76 & 74 & 74 & 74 \\
\hline
\end{tabular}

Figure 2 Time to absolute decline in FVC $\geq 10 \%$ predicted or death over 52 weeks by subgroup. HR was $0.59(95 \% \mathrm{Cl} 0.38$ to 0.89$)$ in patients with baseline FVC $>90 \%$ predicted and $0.61(95 \% \mathrm{Cl} 0.48$ to 0.78$)$ in patients with baseline FVC $\leq 90 \%$ predicted. Treatment-by-subgroup interaction $\mathrm{p}=0.830$.

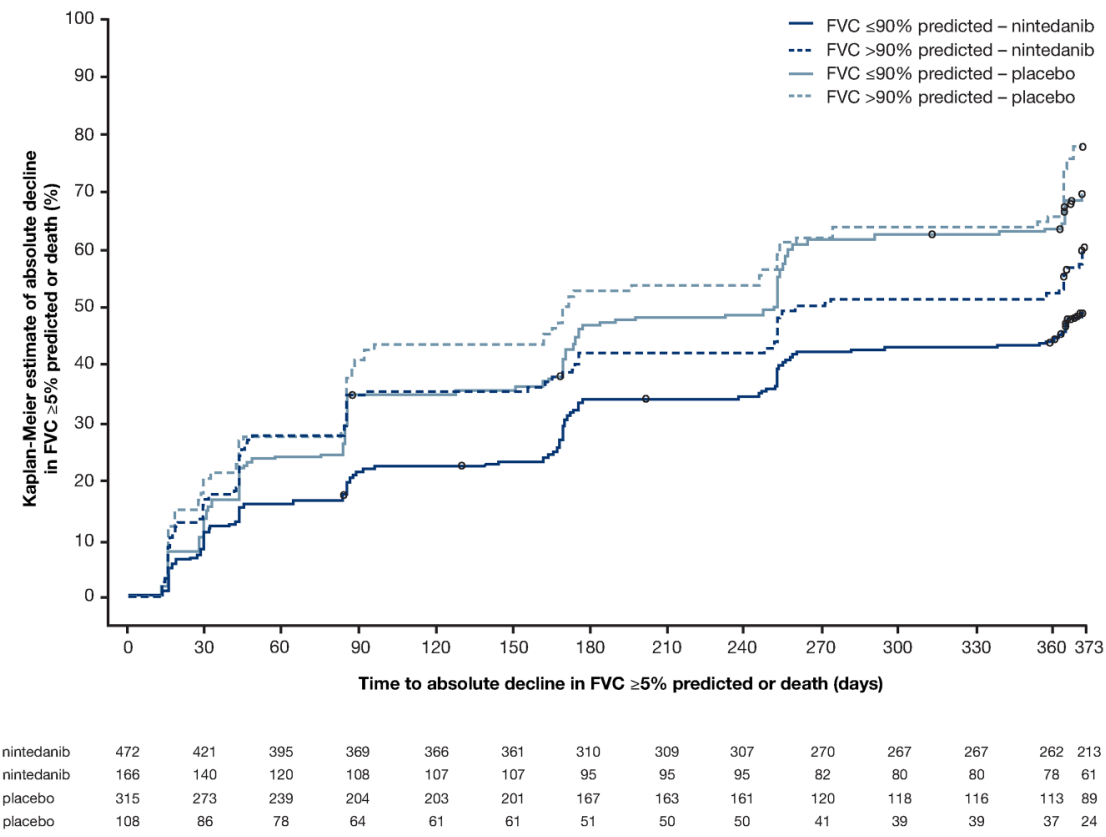

Figure 3 Time to absolute decline in $\mathrm{FVC} \geq 5 \%$ predicted or death over 52 weeks by subgroup. $\mathrm{HR}$ was $0.67(95 \% \mathrm{Cl} 0.50$ to 0.90$)$ in patients with baseline FVC $>90 \%$ predicted and $0.59(95 \% \mathrm{Cl} 0.49$ to 0.71$)$ in patients with baseline FVC $\leq 90 \%$ predicted. Treatment-by-subgroup interaction $\mathrm{p}=0.486$.

significant $(\mathrm{p}=0.956)$, indicating that the treatment effect of nintedanib was not different between the subgroups.

\section{SGRQ total score}

In patients with baseline FVC $>90 \%$ predicted, the adjusted mean change from baseline in SGRQ total score at week 52 was 2.16 in the nintedanib group and 3.02 in the placebo group (difference of -0.87 (95\% CI -3.97 to 2.24)) (see online supplementary figure S2). In patients with baseline FVC $\leq 90 \%$ predicted, the adjusted mean change from baseline in SGRQ total score at week 52 was 4.00 in the nintedanib group and 5.64 in the placebo group (difference of -1.65 (95\% CI -3.60 to 0.31$)$ ) (see online supplementary figure S2). The treatment-by-subgroup interaction $\mathrm{p}$ value was not significant $(p=0.3382)$, indicating that the treatment effect of nintedanib was not different between the subgroups.

\section{Adverse events}

A summary of adverse events is shown in online supplementary table S1. The proportions of patients who had $\geq 1$ adverse event 

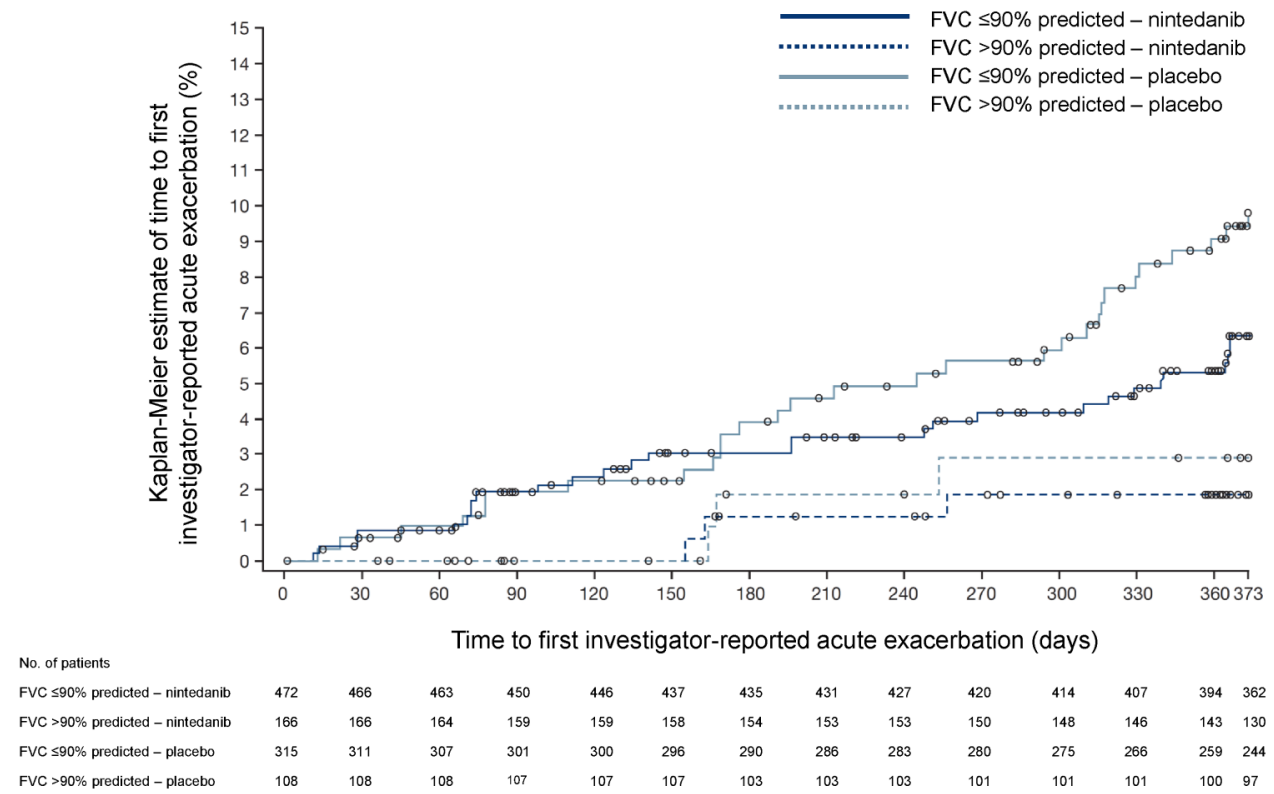

$\begin{array}{llllllllllllll}472 & 466 & 463 & 450 & 446 & 437 & 435 & 431 & 427 & 420 & 414 & 407 & 394 & 362 \\ 166 & 166 & 164 & 159 & 159 & 158 & 154 & 153 & 153 & 150 & 148 & 146 & 143 & 130 \\ 315 & 311 & 307 & 301 & 300 & 296 & 290 & 286 & 283 & 280 & 275 & 266 & 259 & 244 \\ 108 & 108 & 108 & 107 & 107 & 107 & 103 & 103 & 103 & 101 & 101 & 101 & 100 & 97\end{array}$

Figure 4 Time to first acute exacerbation over 52 weeks by subgroup. HR was $0.46(95 \% \mathrm{Cl} 0.09$ to 2.48$)$ in patients with baseline FVC >90\% predicted and $0.66(95 \% \mathrm{Cl} 0.39$ to 1.11) in patients with baseline FVC $\leq 90 \%$ predicted. Treatment-by-subgroup interaction $\mathrm{p}=0.956$.

or $\geq 1$ serious adverse event were comparable between the nintedanib and placebo groups within each subgroup. A higher proportion of patients had $\geq 1$ serious adverse event in the subgroup of patients with baseline FVC $\leq 90 \%$ predicted than FVC $>90 \%$ predicted. Adverse events led to premature discontinuation of study drug in $21.7 \%$ of nintedanib-treated patients with baseline FVC $>90 \%$ predicted and $18.4 \%$ of patients with baseline FVC $\leq 90 \%$ predicted, compared with $7.4 \%$ and $14.6 \%$ of placebo-treated patients in these subgroups, respectively. Diarrhoea was the most frequent adverse event in patients treated with nintedanib, reported in $62.0 \%$ of patients with baseline FVC $>90 \%$ predicted and $62.5 \%$ of patients with baseline FVC $\leq 90 \%$ predicted, compared with $15.7 \%$ and $19.4 \%$ of placebo-treated patients in these subgroups, respectively. Diarrhoea led to premature discontinuation of study drug in $4.2 \%$ of nintedanib-treated patients with baseline FVC $>90 \%$ predicted and $4.4 \%$ of patients with baseline FVC $\leq 90 \%$ predicted, compared with no and $0.3 \%$ of placebo-treated patients in these subgroups, respectively.

\section{DISCUSSION}

Our data from the INPULSIS trials have shown for the first time that placebo-treated patients with a baseline FVC $>90 \%$ predicted have the same rate of FVC decline over the following year as patients with greater impairment in lung volume and the same likelihood of disease progression defined as an absolute decline in FVC $\%$ predicted $\geq 10 \%$ or death. It is notable that over $40 \%$ of placebo-treated patients with an FVC $>90 \%$ predicted at baseline, a subgroup that represented over $25 \%$ of patients recruited into the INPULSIS trials, reached this disease progression endpoint after 1 year. Furthermore, over $75 \%$ of placebo-treated patients with an FVC $>90 \%$ predicted at baseline had an absolute decline in FVC $\%$ predicted of $\geq 5 \%$ after 1 year, suggesting that fewer than one in four patients with preserved lung volume at baseline had stable FVC over the following year. Treatment with nintedanib slowed the annual rate of decline in FVC in patients with FVC $>90 \%$ and $\leq 90 \%$ predicted to the same extent. These are the first data to show the efficacy of an antifibrotic drug in patients with $\mathrm{FVC}>90 \%$ predicted.

Low or worsening FVC has been shown to be a risk factor for acute exacerbations. ${ }^{19-21}$ In this analysis, the proportion of patients who had $\geq 1$ acute exacerbation over 52 weeks was higher in placebo-treated patients with FVC $\leq 90 \%$ than $>90 \%$ predicted $(9.2 \%$ vs $2.8 \%)$. Nintedanib appeared to have the same treatment effect on acute exacerbations in both subgroups, but the interpretation of these data is limited by the low number of acute exacerbations in the subgroup with FVC $>90 \%$ predicted (six events in 274 patients). No difference was observed between subgroups in the effect of nintedanib in change in SGRQ total score, which was small in both subgroups, consistent with the overall patient population.

Data from the INSIGHTS-IPF registry of patients with IPF in clinical practice in Germany showed that patients with less severe impairment in FVC are less likely to be receiving treatment. ${ }^{22}$ However, the earlier that patients with IPF receive treatment, the more lung function remains to be preserved. Further, the clinical course of IPF in an individual patient is unpredictable; patients' pulmonary function may decline rapidly shortly after presentation ${ }^{6} 23$ and acute exacerbations can occur at any point. ${ }^{1}$ It should also be noted that patients with IPF whose lung function appears to be almost normal based on FVC \% predicted may already have lost a substantial amount of functional lung tissue. Given the method used to calculate FVC \% predicted, ${ }^{24}$ some individuals will have had an FVC \% predicted some way above $100 \%$ before developing IPF. The presence of emphysema, a common comorbidity in patients with IPF, ${ }^{25}$ also increases FVC, presumably by mitigating the impact of fibrosis on ventilatory physiology. ${ }^{26}$

Our data argue against a 'watch and wait' approach for the treatment of IPF and support the importance of prompt diagnosis of IPF to enable patients to receive treatment to slow disease progression as soon as possible. ${ }^{27}{ }^{28}$ Data from the CAPACITY and ASCEND trials of pirfenidone have also demonstrated a consistent effect of treatment across subgroups of patients by FVC $\%$ predicted $(\leq 65,65-80,>80 \%)$ at baseline, although patients with $\mathrm{FVC}>90 \%$ predicted were not eligible for the 
ASCEND study. ${ }^{29}$ However, it should be noted that the subgroup analyses of both the nintedanib and pirfenidone trials are based on group averages and these subgroups likely included a number of patients who had no FVC decline during the study period that could be stabilised with therapy. Other limitations include the short duration of treatment, considering that IPF is a chronic disease that may require treatment for longer than 1 year, and premature discontinuation of study medication in $22 \%$ of patients, consistent with treatment discontinuations seen in other clinical trials in patients with IPF with a treatment duration of similar length. ${ }^{11} 30$

A concern might be raised that commencing treatment with nintedanib earlier in the course of IPF might increase the risk that patients would become resistant to the effects of the drug. However, to date, there is no experimental or clinical evidence to suggest the development of resistance to nintedanib in patients with IPF. Indeed, the specificity of nintedanib against growth factor receptors involved in antiangiogenesis (ie, the fibroblast growth factor, platelet-derived growth factor and vascular endothelial growth factor receptors), ${ }^{31}$ together with its antiproliferative activity on fibroblasts prone to secrete growth factors, ${ }^{32}$ argues against potential for treatment resistance. ${ }^{33}$ An interim analysis of INPULSIS-ON, the open-label extension of the INPULSIS trials, has shown that the decline in FVC in patients continuing nintedanib in INPULSIS-ON was similar to the decline in FVC in patients treated with nintedanib in INPULSIS, suggesting that the effect of nintedanib on slowing disease progression is maintained for at least 3 years. ${ }^{34}$

In conclusion, in this analysis of pooled data from the INPULSIS trials, the annual rate of decline in FVC was similar in placebo-treated patients with preserved lung volume (FVC $>90 \%$ predicted) at baseline as in patients with greater impairment in lung volume. Nintedanib slowed the decline in lung function independent of the degree of FVC impairment at baseline, with a similar adverse event profile in both subgroups. These findings support the concept of offering treatment to patients with IPF and preserved lung volumes at the time of diagnosis, until there are markers that predict individual disease course.

Acknowledgements Medical writing assistance, supported financially by Boehringer Ingelheim, was provided by Julie Fleming and Wendy Morris of Fleishman-Hillard Group, London, UK, during the preparation of this article. The authors were fully responsible for all content and editorial decisions, and were involved at all stages of manuscript development and have approved the final version.

Contributors All the authors except WT were involved in the study design. All the authors were involved in analysis or interpretation of data and revising the manuscript for important intellectual content. All the authors have approved the final version of the manuscript.

Funding The INPULSIS trials were funded by Boehringer Ingelheim. Boehringer Ingelheim was involved in the study design, in the analysis and interpretation of the data and in the writing of this manuscript.

Competing interests MK reports receipt of grants and personal fees from Boehringer Ingelheim and Roche; personal fees from GlaxoSmithKline, Gilead, AstraZeneca, ProMetic and Genoa; and grants from Actelion, Respivert, the Canadian Institute for Health Research and the Canadian Pulmonary Fibrosis Foundation. LR reports receipt of grants and personal fees from Boehringer Ingelheim for being a member of the INPULSIS steering committee and co-principal investigator of the trials; grants and personal fees from InterMune for being a member of an advisory board; personal fees from Medlmmune (advisory board member), Biogen Idec (consulting), Sanofi-Aventis (consulting), Roche (advisory board member), Takeda (advisory board member), ImmuneWorks (consulting), Shionogi (speaker honoraria) and GlaxoSmithKline (advisory board member). JB reports serving as an ILD expert for the current international IPF guidelines; serving as Chair or member of the steering committees for the Panorama, BUILD-3, Artemis-IPF, Artemis-PH and RISE-IIP clinical trials; receipt of grants and personal fees from Actelion and InterMune; and personal fees from Boehringer Ingelheim,
Grünenthal, Gilead, Bayer, Roche and GlaxoSmithKline. TMM reports receipt of grants and personal fees from GlaxoSmithKline (advisory board member); grants from Novartis; grants and non-financial support from UCB; non-financial support from Takeda; personal fees from Boehringer Ingelheim, InterMune, Lanthio,

Sanofi-Aventis, AstraZeneca, Roche, Bayer, Biogen Idec, Cipla, DOSA, ProMetic and Galapagos; and serving as an investigator in an ongoing Gilead phase 2b study. WT, SSt and CH are employees of Boehringer Ingelheim. RMdB has served as a steering committee member for Boehringer Ingelheim and InterMune, and as an advisory board member for GlaxoSmithKline and Actelion.

Ethics approval The clinical protocol was approved by an independent ethics committee or institutional review board at each participating centre.

Provenance and peer review Not commissioned; externally peer reviewed.

Open Access This is an Open Access article distributed in accordance with the Creative Commons Attribution Non Commercial (CC BY-NC 4.0) license, which permits others to distribute, remix, adapt, build upon this work non-commercially, and license their derivative works on different terms, provided the original work is properly cited and the use is non-commercial. See: http://creativecommons.org/ licenses/by-nc/4.0/

\section{REFERENCES}

1 Raghu G, Collard HR, Egan JJ, et al. An official ATS/ERS/JRS/ALAT statement: idiopathic pulmonary fibrosis: evidence-based guidelines for diagnosis and management. Am J Respir Crit Care Med 2011;183:788-824.

2 Kim HJ, Perlman D, Tomic R. Natural history of idiopathic pulmonary fibrosis. Respir Med 2015;109:661-70.

3 Zappala CJ, Latsi PI, Nicholson AG, et al. Marginal decline in forced vital capacity is associated with a poor outcome in idiopathic pulmonary fibrosis. Eur Respir $\mathrm{J}$ 2010;35:830-6.

4 du Bois RM, Weycker D, Albera C, et al. Forced vital capacity in patients with idiopathic pulmonary fibrosis: test properties and minimal clinically important difference. Am J Respir Crit Care Med 2011;184:1382-9.

5 Nathan SD, Shlobin OA, Weir N, et al. Long-term course and prognosis of idiopathic pulmonary fibrosis in the new millennium. Chest 2011;140:221-9.

6 Schmidt SL, Tayob N, Han MK, et al. Predicting pulmonary fibrosis disease course from past trends in pulmonary function. Chest 2014;145:579-85.

7 Taniguchi $\mathrm{H}$, Ebina $\mathrm{M}$, Kondoh $\mathrm{Y}$, et al. Pirfenidone in idiopathic pulmonary fibrosis. Eur Respir J 2010;35:821-9.

8 King TE Jr, Brown KK, Raghu G, et al. BUILD-3: a randomized, controlled trial of bosentan in idiopathic pulmonary fibrosis. Am J Respir Crit Care Med 2011;184:92-9.

9 Richeldi L, Costabel U, Selman M, et al. Efficacy of a tyrosine kinase inhibitor in idiopathic pulmonary fibrosis. N Engl J Med 2011;365:1079-87.

10 Raghu G, Million-Rousseau R, Morganti A, et al. Macitentan for the treatment of idiopathic pulmonary fibrosis: the randomised controlled MUSIC trial. Eur Respir $J$ 2013;42:1622-32.

11 King TE Jr, Bradford WZ, Castro-Bernardini S, et al. A phase 3 trial of pirfenidone in patients with idiopathic pulmonary fibrosis. N Engl J Med 2014;370:2083-92.

12 Richeldi L, du Bois RM, Raghu G, et al. Efficacy and safety of nintedanib in idiopathic pulmonary fibrosis. N Engl J Med 2014;370:2071-82.

13 Wollin L, Wex E, Pautsch A, et al. Mode of action of nintedanib in the treatment of idiopathic pulmonary fibrosis. Eur Respir J 2015;45:1434-45.

14 Raghu G, Rochwerg B, Zhang Y, et al. An official ATS/ERS/JRS/ALAT clinical practice guideline: treatment of idiopathic pulmonary fibrosis. An update of the 2011 clinical practice guideline. Am J Respir Crit Care Med 2015;195:e3-19.

15 Kolb M, Collard HR. Staging of idiopathic pulmonary fibrosis: past, present and future. Eur Respir Rev 2014;23:220-4.

16 National Institute for Health and Care Excellent (NICE).Pirfenidone for treating idiopathic pulmonary fibrosis. NICE technology appraisal guidance 282. Issued April 2013. http://guidance.nice.org.uk/ta282 (accessed 25 Feb 2016).

17 Costabel U, Inoue Y, Richeldi L, et al. Efficacy of nintedanib in idiopathic pulmonary fibrosis across pre-specified subgroups in INPULSIS $®$. Am J Respir Crit Care Med 2016:193:178-85.

18 Kolb M, Richeldi L, Kimura T, et al. Effect of baseline FVC on decline in lung function with nintedanib in patients with IPF: results from the INPULSIS $尺$ trials [abstract]. Am J Respir Crit Care Med 2015;191:A1021.

19 Kondoh Y, Taniguchi H, Katsuta T, et al. Risk factors of acute exacerbation of idiopathic pulmonary fibrosis. Sarcoidosis Vasc Diffuse Lung Dis 2010;27:103-10.

20 Song JW, Hong SB, Lim CM, et al. Acute exacerbation of idiopathic pulmonary fibrosis: incidence, risk factors and outcome. Eur Respir J 2011;37:356-63.

21 Collard HR, Yow E, Richeldi L, et al. Suspected acute exacerbation of idiopathic pulmonary fibrosis as an outcome measure in clinical trials. Respir Res 2013;14:73.

22 Behr J, Kreuter M, Hoeper MM, et al. Management of patients with idiopathic pulmonary fibrosis in clinical practice: the INSIGHTS-IPF registry. Eur Respir J 2015;461:186-96. 
23 Salisbury ML, Xia M, Zhou Y, et al. Idiopathic pulmonary fibrosis: gender-agephysiology index stage for predicting future lung function decline. Chest 2016;149:491-8.

24 Quanjer PH, Tammeling GJ, Cotes JE, et al. Lung volumes and forced ventilatory flows. Eur Respir J 1993;6(Suppl 16):5-40.

25 Raghu G, Amatto VC, Behr J, et al. Comorbidities in idiopathic pulmonary fibrosis patients: a systematic literature review. Eur Respir J 2015;46:1113-30.

26 Ryerson CJ, Hartman T, Elicker BM, et al. Clinical features and outcomes in combined pulmonary fibrosis and emphysema in idiopathic pulmonary fibrosis. Chest 2013;144:234-40.

27 Cottin V, Richeldi L. Neglected evidence in idiopathic pulmonary fibrosis and the importance of early diagnosis and treatment. Eur Respir Rev 2014;23: 106-10.

28 Thickett DR, Kendall C, Spencer LG, et al. Improving care for patients with idiopathic pulmonary fibrosis (IPF) in the UK: a round table discussion. Thorax 2014;69:1136-40.
29 Noble PW, Albera C, Bradford WZ, et al. Pirfenidone for idiopathic pulmonary fibrosis: analysis of pooled data from three multinational phase 3 trials. Eur Respir J 2016:47:243-53.

30 Martinez FJ, de Andrade JA, Anstrom KJ, et al. Idiopathic Pulmonary Fibrosis Clinical Research Network. Randomized trial of acetylcysteine in idiopathic pulmonary fibrosis. N Engl J Med 2014;370:2093-101.

31 Hilberg F, Roth GJ, Krssak M, et al. BIBF 1120: triple angiokinase inhibitor with sustained receptor blockade and good antitumor efficacy. Cancer Res 2008;68:4774-82.

32 Hostettler KE, Zhong J, Papakonstantinou E, et al. Anti-fibrotic effects of nintedanib in lung fibroblasts derived from patients with idiopathic pulmonary fibrosis. Respir Res 2014;15:157.

33 Fang WB, Yao M, Cheng N. Priming cancer cells for drug resistance: role of the fibroblast niche. Front Biol 2014;9:114-26.

34 Crestani B, Quaresma M, Kaye M, et al. Long-term treatment with nintedanib in patients with IPF: an update from INPULSIS-ON. Eur Respir J 2016;48(Suppl 60): OA4960. 